\title{
CHRONIC GASTRITIS CLINICAL FEATURES AND STOMACH FUNCTIONAL STATE DURING NONSTEROIDAL ANTI-INFLAMMATORY DRUGS ADMINISTRATION IN PATIENTS WITH OSTEOARTHRITIS
}

\author{
Maxim Zak \\ Department of General Practice - Family Medicine \\ Kharkiv National Medical University \\ 4 Nauky ave., Kharkiv, Ukraine, 61022 \\ ukrgastro@gmail.com \\ Lyudmila Pasiyeshvili \\ Department of General Practice - Family Medicine \\ Kharkiv National Medical University \\ 4 Nauky ave., Kharkiv, Ukraine, 61022
}

\begin{abstract}
Aim. Determination of chronic gastritis clinical features and stomach functional state during nonsteroidal anti-inflammatory drugs (NSAID) administration in patients with osteoarthritis (OA).

Materials and methods. 122 patients with OA and verified chronic gastritis (CG) (50 males and 72 females) aged 42 to 64 years (mean age $-49.65 \pm 3.51$ ) were observed. Depending on gastritis morphological form, patients were divided into 2 groups: 54 patients with OA in combination with non-atrophic gastritis (NAG) were included into the group I, 68 patients with OA in combination with atrophic gastritis (AG) - into group II. 40 patients with OA without concomitant gastroduodenal pathology in anamnesis were included into the group III. All patients obtained selective NSAID for OA treatment: Meloxicam 15 mg daily or Nimesulide $200 \mathrm{mg}$ daily. The control group was formed by 20 persons, which were found to be healthy after a complex examination. Stomach acid-forming function was investigated using esophageal $\mathrm{pH}$ monitoring. In the gastric contents, which obtained by aspiration, concentration of sialic acids glycoproteins, fucose, and hexosamines was determined.

Results. Clinical picture of NSAID gastropathy at NAG characterized by abdominal pain of varying intensity and not associated with eating, but in patients with AG severity and discomfort symptoms dominated over weakly expressed pain syndrome. As a result of NSAID, in the group I dyspepsia developed in 31 (57.4\%), and erosive gastropathy developed in 9 (16.7 \%) patients. In the group II, erosive gastropathy and dyspepsia were observed in $15(22.1 \%)$ and in 35 (51.5 \%) patients, respectively. In the group III, erosive gastropathy was observed 3.3 times $\left(\chi^{2}=84.33 ; p=0.009\right)$ and 4.4 times $\left(\chi^{2}=36.78 ; p=0.002\right)$ less than in groups I and II, respectively. In $25 \%$ patients of the group I after NSAID therapy intragastric $\mathrm{pH}$ increased from normacid to hyperacid status. In the group II, NSAID administration led to stomach mucosal (SM) protective factors depletion, which was observed in $73.3 \%$ and in $28.6 \%$ of patients with erosive gastropathy and NSAID-associated dyspepsia, respectively. At AG with erosive gastropathy, unlike NAG, several protective factors simultaneous reduction was observed.

Coonclusion. In anamnesis, CG factor at selective NSAID administration (Meloxicam and Nimesulide) in relation to OA significantly increases the risk of erosive gastropathy, compared with patients without CG in anamnesis. At OA NSAID administration in patients with NAG led to gastric contents acidification and in patients with AG - to SM protective factors depletion (glycoprotein, fucose, and hexosamine).
\end{abstract}

Keywords: chronic gastritis, osteoarthritis, nonsteroidal anti-inflammatory drugs.

\section{Introduction}

Gastrointestinal safety problem at nonsteroidal anti-inflammatory drugs (NSAID) using in patients with chronic gastritis (CG) is relevant and in many respects unsolved problem [1-3]. Nowadays it is conclusively proven, that the presence of a peptic ulcer in anamnesis belongs to the leading factors of risk of NSAID-development and related gastric bleeding [4]. At CG, as well as at peptic ulcer, imbalance between aggression factors and stomach mucosal (SM) protection are the main mechanisms of pathological process formation. Our previous studies have shown that at atrophic gastritis (AG) SM resistance factors deficiency more pronounced, comparing with 
non-atrophic gastritis (NAG) [4]. Nevertheless, the problem of gastropathy/dyspepsia development at NSAID therapy in patients with $\mathrm{CG}$ in anamnesis remains unsolved.

Osteoarthritis $(\mathrm{OA})$ is the most prevalent rheumatic disease. OA in females leads to reduction of life expectancy in average of 10-15 years [1, 2, 6, 7]. It was determined that reduction of life expectancy in the elderly is more dependent on the pain intensity, than the presence or absence of coronary artery disease, hypertension and other diseases. That is why an adequate analgesia using NSAID is a strategically important component of OA treatment [6]. To achieve the analgesic effect, it is often necessary to resort to high doses and prolonged use of NSAID, which in turn increases the risk of gastropathy [7-9]. Gastropathy, induced by NSAID therapy, is characterized by development of ulcers and SM erosion of gastroduodenal zone [10-12]. According to Sydney classification system, NSAID gastropathies refer to the reactive forms of gastritis - C type [13].

Several mechanisms of NSAID damaging action to SM are known. Most of NSAID from the chemical point of view have acid properties with dissociation constant (pKa) 3-5. In the stomach acidic environment, these molecules are easily ionized and penetrate the epithelial cells of gastroduodenal SM, accumulating there and providing a direct damaging effect [14, 15]. It was determined, that some time after the administration of these drugs, penetration of hydrogen and sodium ions into SM increasing is observed. Some NSAID can directly inhibit mucin synthesis and bicarbonates secretion. After these drugs administration, hydrophobic layer on the SM surface is damaged, phospholipids composition is depleted, and secretion of gastric mucosal components is decreased. The mentioned factors cause the decrease in gastric epithelium protective properties and its ability to adequately repair. Besides, NSAID can influence on leukotrienes synthesis, which decreasing leads to mucus reduction [16-18].

Selective Cyclooxygenase-2 (COX-2) blockers, on the one hand are highly effective for articular syndrome treatment in patients with $\mathrm{OA}$, and on the other hand have gastrointestinal safety high profile [1, 5]. But these drugs safety was proved in patients with intact SM [7, 14]. At the same time at CG a number of inflammatory and degenerative processes in the gastric epithelium develops [19], which, possibly may cause the increased risk of erosive gastropathy at NSAID-therapy.

\section{Aim of research}

Determination of chronic gastritis clinical features and stomach functional state during NSAID administration in patients suffering from OA.

\section{Materials and methods}

122 patients with OA and verified chronic gastritis (CG) in anamnesis (50 males and 72 females) aged 42 to 64 years (mean age $-49.65 \pm 3.51$ ) were observed. Depending on gastritis morphological form, patients were divided into 2 groups: 54 patients with OA in combination with non-atrophic gastritis (NAG) were included into the group I, 68 patients with OA in combination with atrophic gastritis (AG) - into the group II. 40 patients with OA without concomitant gastroduodenal pathology in anamnesis were included into the group III. OA diagnostics was implemented in accordance to the national and international recommendations [2, 5]. For OA treatment, patients obtained selective NSAID Meloxicam $15 \mathrm{mg}$ daily or Nimesulide $200 \mathrm{mg}$ daily. CG diagnosis was made on the basis of Sydney-Houston classification and OLGA system [7, 20]. To determine laboratory criteria of biochemical indicators of the factors of SM aggression and defense, 20 persons were examined and were found to be healthy - the control group.

Stomach acid-forming function was investigated using esophageal $\mathrm{pH}$ monitoring and "AG-1D-01" pH-meter system at the location of the electrode distal end at the antrum level. Mobile drive fixed the intragastric $\mathrm{pH}$ change every 8 seconds. Cancellation of antisecretory drugs was an obligatory condition, in case of reception, at least 4 days before research. Using "AG-1D-01" software system, $\mathrm{pH}$ arithmetic average was calculated, and function intervals (FI) distribution. Gastric juice was collected by aspiration during gastroscopy. In the gastric contents, concentration of sialic acids glycoproteins, fucose, and hexosamines was determined [4].

The present examination was carried out in connection with gastroduodenal pathology worsening. 


\section{Results}

In the majority - 102 patients - CG was diagnosed firstly; then OA joined to it. Less commonly, in 20 cases, CG preceded to OA verification. This fact is connected with the circumstance that as a rule CG occurs at young age, and OA is specific for middle and senior age groups. At the same time, CG may be asymptomatic for a long time, and when patients seek medical care, SM atrophic changes is already diagnosed in them. In such cases OA was diagnosed earlier than CG.

As a result of NSAID, in the group I dyspepsia developed in 31 (57.4 \%), and erosive gastropathy developed in $9(16.7 \%)$ patients. In the group II, erosive gastropathy and dyspepsia were observed in $15(22.1 \%)$ and in $35(51.5 \%)$ patients, respectively (Fig. 1). The noteworthy fact, that SM erosive lesions as NSAID gastropathies in patients with AG occurred 1.3 times more often than at NAG (Fig. 1).

At the same time, the frequency of undesirable side effects at NSAID administration in patients with OA without gastroduodenal pathology was significantly less. Therefore, in the group III, dyspeptic syndrome developed in 2.9 times $\left(\chi^{2}=26.0 ; p=0.02\right)$ and 2.6 times $\left(\chi^{2}=94.35 ; p=0.03\right)$ less than in groups I and II, respectively; erosive gastropathy was observed 3.3 times $\left(\chi^{2}=84.33 ; p=0.009\right)$ and 4.4 times $\left(\chi^{2}=36.78 ; p=0.002\right)$ less than in groups I and II, respectively (Fig. 1).

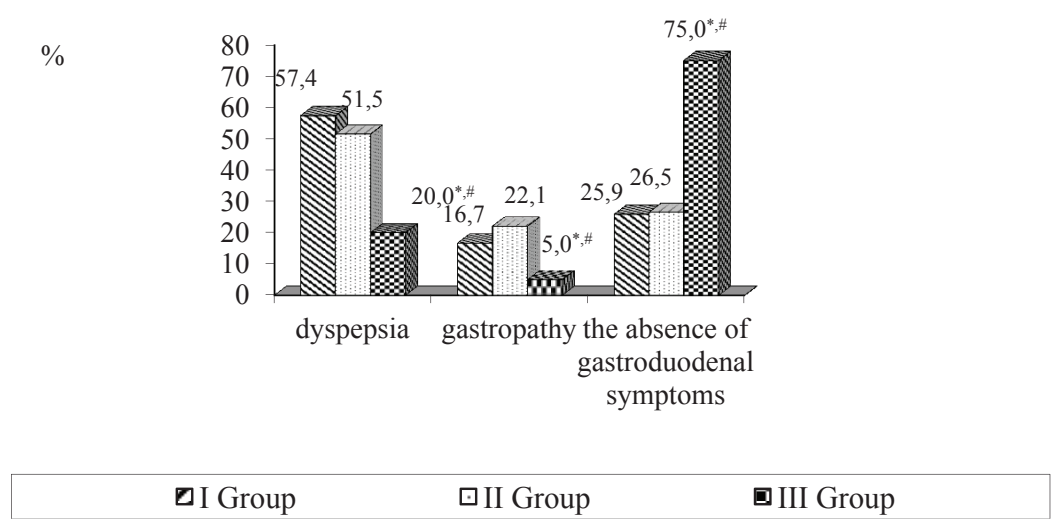

Fig. 1 Frequency of dispersion and gastropathy at selective NSAID therapy: a - I Group; 口 - II Group; - - III Group; * - significant difference compared with Group I $(\mathrm{P}<0,05)$; ** - significant difference compared with Group II $(\mathrm{P}<0,01)$

Duration of patients' examination before gastroduodenal pathology symptoms appear was from 1 week to 3 months. Nevertheless, in most patients of groups I and II - 28 (70.0\%) of 40 and $39(78.0 \%)$ of 50 patients, respectively, "gastritic" character complaints developed during the first month after the beginning of NSAID therapy. At the same time, at OA without concomitant illness, the syndrome of abdominal pain and/or dyspepsia occurred mainly in the third month after the beginning of NSAID therapy.

The main clinical syndrome during erosive gastropathy development in patients of the group I was epigastric pain not associated with eating. Subjectively, patients more frequently reported about moderate ( 6 persons $-66.7 \%$ of 9 ) and high ( 2 persons $-22.2 \%$ of 9 ) intensity of pain. In the group II, clinical symptomatology of erosive gastropathy characterized by mildness and a small amount of symptoms, unlike the group I. The main clinical manifestations were: periodic feeling of heaviness and discomfort in the epigastric region, mostly after eating (in 12 persons $-79.9 \%$ of 15$)$, epigastric pain - in $3(20.1 \%)$ of 5 persons.

Then, we analyzed the dynamics of stomach acid status in the CG primary treatment and during NSAID therapy in erosive gastropathy/dyspepsia development cases. It was found, that in $10(25.0 \%)$ of 40 patients of the group I after NSAID administration intragastric $\mathrm{pH}$ increased from normacid to hyperacid status (Table 1). In patients of the group II, hyperacidity was absent before NSAID therapy, and after NSAID administration was shown in 3 (6.0\%) of 50 patients; besides, in 10 (20.0\%) patients hyperacidity transformed into normacidity (Table 1). Significant changes in pepsin level during NSAID therapy were not observed (Table 2). 
Table 1

Stomach acid status and pepsin level in examined patients during primary treatment and after NSAID therapy

\begin{tabular}{|c|c|c|c|c|}
\hline & \multicolumn{2}{|c|}{ NAG with OA $(n=40)$} & \multicolumn{2}{|c|}{ AG with OA $(n=50)$} \\
\hline & $\begin{array}{c}\text { During } \\
\text { primary treatment }\end{array}$ & $\begin{array}{c}\text { During } \\
\text { NSAID treatment }\end{array}$ & $\begin{array}{c}\text { During } \\
\text { primary treatment }\end{array}$ & $\begin{array}{c}\text { During } \\
\text { NSAID therapy }\end{array}$ \\
\hline Hyperacidity & $\begin{array}{l}8(20,0 \%) \\
1,49 \pm 0,07\end{array}$ & $\begin{array}{c}18(45,0 \%) \\
1,33 \pm 0,18\end{array}$ & - & $\begin{array}{c}3(6,0 \%) \\
1,49 \pm 0,10\end{array}$ \\
\hline Normacidity & $\begin{array}{c}32(80,0 \%) \\
2,18 \pm 0,04\end{array}$ & $\begin{array}{c}22(55,0 \%) \\
1,85 \pm 0,19\end{array}$ & $\begin{array}{l}32(64,0 \%) \\
2,12 \pm 0,15^{*}\end{array}$ & $\begin{array}{l}39(78,0 \%) \\
1,82 \pm 0,59 *\end{array}$ \\
\hline Hypoacidity & - & - & $\begin{array}{c}18(36,0 \%) \\
1,79 \pm 0,05\end{array}$ & $\begin{array}{l}8(16,0 \%) \\
3,23 \pm 0,68\end{array}$ \\
\hline
\end{tabular}

NSAID therapy led to SM protective factors depletion, which was particularly pronounced at $\mathrm{AG}$ with OA. In the group I, decrease in glycoprotein level was observed in $2(5.0 \%)$ patients, only with NSAID gastropathy (Table 2). In the other cases, including NSAID dyspepsia, values instability was within the range comparing with the control group. In the group II, a slightly different situation was observed: NSAID administration led to SM protective factors depletion in 11 (73.3 \%) of 15 and in 10 (28.6\%) of 35 patients suffering from NSAID gastropathy and NSAID dyspepsia, respectively (Table 2). Besides, several protective factors simultaneous reduction was observed at AG, unlike NAG. Thus, among 15 patients of the group II with erosive gastropathy, one resistance factor reduction was observed in $6(40.0 \%)$, two factors - in $3(20.1 \%)$, three factors - in $2(13.4 \%)$ patients. At NSAID dyspepsia the lack of one factor was observed in $7(20.0 \%)$, two factors - in $3(8.6 \%)$ of 35 patients. Decrease in the average levels of glycoprotein, hexosamine and fucose was the most important.

Table 2

SM protective factors status during NSAID therapy in patients suffering from CG with OA

\begin{tabular}{|c|c|c|c|c|c|}
\hline \multirow[b]{2}{*}{ Index } & \multirow[b]{2}{*}{$\begin{array}{l}\text { Control group } \\
\quad(\mathbf{n}=\mathbf{2 0})\end{array}$} & \multicolumn{2}{|c|}{ NAG with OA $(n=40)$} & \multicolumn{2}{|c|}{ AG with $\mathrm{OA}(\mathrm{n}=50)$} \\
\hline & & $\begin{array}{c}\text { During } \\
\text { primary treatment }\end{array}$ & $\begin{array}{c}\text { During } \\
\text { NSAID therapy }\end{array}$ & $\begin{array}{c}\text { During } \\
\text { primary treatment }\end{array}$ & $\begin{array}{c}\text { During } \\
\text { NSAID therapy }\end{array}$ \\
\hline Glycoprotein, $\mathrm{mg} / \mathrm{ml}$ & $0,072 \pm 0,009$ & $0,068 \pm 0,005$ & $0,061 \pm 0,003$ & $0,051 \pm 0,004^{*}$ & $0,032 \pm 0,007^{\#}$ \\
\hline Hexosamine, $\mathrm{mmol} / \mathrm{l}$ & $0,928 \pm 0,091$ & $0,910 \pm 0,040$ & $0,910 \pm 0,040$ & $0,761 \pm 0,050$ & $0,560 \pm 0,060^{\#}$ \\
\hline Fucose, $\mathrm{mmol} / \mathrm{l}$ & $1,185 \pm 0,110$ & $1,190 \pm 0,031$ & $1,112 \pm 0,025$ & $1,080 \pm 0,070$ & $0,710 \pm 0,060^{\$ \$ * * \#}$ \\
\hline Sialic acids, mmol/1 & $0,116 \pm 0,009$ & $0,110 \pm 0,005$ & $0,101 \pm 0,005$ & $0,160 \pm 0,020$ & $0,210 \pm 0,090^{{ }^{*}}$ \\
\hline
\end{tabular}

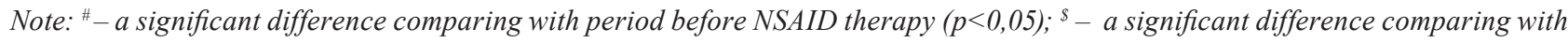
the control group $(p<0,05)$

\section{Discussion of Results of Research}

The obtained results point to the fact, that CG index during the selective NSAID therapy (Meloxicam and Nimesulide) significantly - in 2.9 times less $\left(\chi^{2}=26.0 ; p=0.02\right)$ at NAG and 2.6 times less $\left(\chi^{2}=94.35 ; p=0.03\right)$ at AG increases the risk of erosive gastropathy and dyspepsia, respectively, development. The presence of atrophic changes in SM is characterized by the tendency $(\mathrm{p}>0.05)$ to a higher risk of erosive gastropathy development, comparing with NAG. 
Clinical picture of NSAID gastropathy at NAG characterized by abdominal pain of varying intensity and not associated with eating, but in patients with AG severity and discomfort symptoms dominated over weakly expressed pain syndrome.

The use of NSAID led to gastric contents acidification. In the group I, one in four patients had increased intragastric $\mathrm{pH}$ from normacid to hyperacid level. In the group II, one in five patients had hypoacid transformation to normacid. Nevertheless, in most $-93.0 \%$ patients with AG the acid and pepsin aggression didn't play a significant part in NSAID gastropathy and dyspepsia development, due to remained hypoacidity or normacidity. In our opinion, one of the key pathogenetic components of NSAID erosive gastropathy development in patients with AG was SM protective factors (glycoprotein, fucose, and hexosamine) depletion, which $42.0 \%$ of patients had.

\section{Conclusion}

1. Meloxicam or Nimesulide therapy of osteoarthritis in patients with chronic gastritis in anamnesis increases the risk of NSAID erosive gastropathy in 2.9 times, compared with patients without concomitant gastroduodenal pathology. Atrophic gastritis is being associated with the tendency $(p>0,05)$ of the higher risk of erosive gastropathy development.

2. Selective NSAID administration for osteoarthritis treatment in patients with non-atrophic gastritis causes intragastric $\mathrm{pH}$ acidification in $25.0 \%$ of cases.

3. The use of selective NSAID for osteoarthritis treatment led to stomach mucosal protective factors depletion in $73.3 \%$ of patients suffering from erosive atrophic gastritis.

\section{References}

[1] Kuryata, A. V., Grechanik, M. M. (2014). Problema lecheniya sustavnoy boli: focus na bezopasnost'. Health of Ukraine, 6, 43-44.

[2] Kovalenko, V. M., Bortkiewicz, O. P. (2010). Osteoartroz: practichna nastanova. Kyiv: Morion, 607.

[3] McCarberg, B. H., Cryer, B. (2015). Evolving Therapeutic Strategies to Improve Nonsteroidal Anti-inflammatory Drug Safety. American Journal of Therapeutics, 22 (6), e167-e178. doi: 10.1097/ mjt.0000000000000123

[4] Zak, M. Y., Mosiychuk, L. M. (2011). Hronichniygastrit i peredrakshlunka: practichniyposibnik. Dnipropetrovs'k: Siaprint, 71.

[5] Hochberg, M. C., Altman, R. D., April, K. T., Benkhalti, M., Guyatt, G., McGowan, J. et. al. (2012). American College of Rheumatology 2012 recommendations for the use of nonpharmacologic and pharmacologic therapies in osteoarthritis of the hand, hip, and knee. Arthritis Care \& Research, 64 (4), 465-474. doi: 10.1002/acr.21596

[6] Courties, A., Gualillo, O., Berenbaum, F., Sellam, J. (2015). Metabolic stress-induced joint inflammation and osteoarthritis. Osteoarthritis and Cartilage, 23 (11), 1955-1965. doi: 10.1016/j.joca.2015.05.016

[7] Narouze, S., Souzdalnitski, D. (2015). Obesity and chronic pain: opportunities for better patient care. Pain Management, 5 (4), 217-219. doi: 10.2217/pmt.15.16

[8] Matsui, H., Shimokawa, O., Kaneko, T., Nagano, Y., Rai, K., Hyodo, I. (2011). The pathophysiology of non-steroidal anti-inflammatory drug (NSAID)-induced mucosal injuries in stomach and small intestine. Journal of Clinical Biochemistry and Nutrition, 48 (2), 107-111. doi: 10.3164/jcbn.10-79

[9] Boltin, D., Niv, Y. (2014). Pharmacological and alimentary alteration of the gastric barrier. Best Practice \& Research Clinical Gastroenterology, 28 (6), 981-994. doi: 10.1016/j.bpg.2014.09.001

[10] Sinha, M., Gautam, L., Shukla, P. K., Kaur, P., Sharma, S., Singh, T. P. (2013). Current Perspectives in NSAID-Induced Gastropathy. Mediators of Inflammation, 2013, 1-11. doi: 10.1155/2013/258209

[11] Uyanikoglu, A., Danalioglu, A., Akyuz, F., Ermis, F., Gulluoglu, M., Kapran, Y. et. al. (2012). Etiological factors of duodenal and gastric ulcers. The Turkish Journal of Gastroenterology, 23 (2), 99-103. doi: $10.4318 /$ tjg. 2012.0435

[12] Kayacetin, S., \& Guresci, S. (2014). What is gastritis? What is gastropathy? How is it classified? The Turkish Journal of Gastroenterology, 25 (3), 233-247. doi: 10.5152/tjg.2014.7906 
[13] Dixon, M. F., Genta, R. M., Yardley, J. H., Correa, P. (1996). Classification and Grading of Gastritis. The American Journal of Surgical Pathology, 20 (10), 1161-1181. doi: 10.1097/00000478199610000-00001

[14] Blackler, R. W., De Palma, G., Manko, A., Da Silva, G. J., Flannigan, K. L., Bercik, P. et. al. (2015). Deciphering the pathogenesis of NSAID enteropathy using proton pump inhibitors and a hydrogen sulfide-releasing NSAID. American Journal of Physiology - Gastrointestinal and Liver Physiology, 308 (12), G994-G1003. doi: 10.1152/ajpgi.00066.2015

[15] Kwiecień, S., Magierowska, K., Śliwowski, Z., Wójcik, D., Magierowski, M., Brzozowski, T. (2015). New insight into the mechanisms of gastroduodenal injury induced by nonsteroidal anti-inflammatory drugs: practical implications. Polskie Archiwum Medycyny Wewnetrznej, 125 (3), 191-198.

[16] Maguilnik, I., Neumann, W. L., Sonnenberg, A., Genta, R. M. (2012). Reactive gastropathy is associated with inflammatory conditions throughout the gastrointestinal tract. Alimentary Pharmacology \& Therapeutics, 36 (8), 736-743. doi: 10.1111/apt.12031

[17] Roth, S. H. (2012). Coming to Terms with Nonsteroidal Anti-Inflammatory Drug Gastropathy. Drugs, 72 (7), 873-879. doi: 10.2165/11633740-000000000-00000

[18] O’Connor, A., O’Moráin, C. (2014). Digestive Function of the Stomach. Digestive Diseases, 32 (3), 186-191. doi: 10.1159/000357848

[19] Arismendi-Morillo, G., Hernández, I., Mengual, E., Abreu, N., Molero, N., Fuenmayor, A. et. al. (2013). Estimación de riesgo de cáncer gástrico en pacientes con gastritis crónica asociada a la infección por Helicobacter pylori en un escenario clínico. Revista de Gastroenterología de México, 78 (3), 135-143. doi: 10.1016/j.rgmx.2013.01.004

[20] Rugge, M., de Boni, G., Pennelli, M. (2010). Gastritis OLGA - staging \& gastric cancer risk: a twelve year clinico-pathological follow-up study (England) Minerva Gastroenterol. Dietol., 56 (1), 13-17. 